\title{
DESENVOLVIMENTO REGIONAL E GEOPROCESSAMENTO: CONTRIBUIÇÕES PARA ZONEAMENTO ECONÔMICO E AMBIENTAL DE RIO BRANCO - AC/ZEAS
}

\author{
REGIONAL DEVELOPMENT AND GEOGRAPHICAL \\ INFORMATION SYSTEM -GIS: CONTRIBUTION TO \\ ENVIRONMENTAL AND ECONOMICAL ZONING OF RIO \\ BRANCO
}

\author{
Lorena Costa Irmão \\ Universidade Federal do Acre - Rio Branco - AC - Brasil \\ Raimundo Cláudio Gomes Maciel \\ Universidade Federal do Acre - Rio Branco - AC - Brasil
}

\begin{abstract}
Resumo: Com a crescente demanda dos Governos e Sociedade por informações, sejam elas do meio rural ou urbano, expressa nos diversos Zoneamentos, o Geoprocessamento tem sido uma ferramenta essencial, pois utiliza técnicas matemáticas e computacionais para o tratamento da informação geográfica e vem influenciando de maneira crescente as áreas de Cartografia, Análise de Recursos Naturais, Transportes, Comunicação, Planejamento Urbano, Regional e Rural. Isso tem contribuído sobremaneira para as estratégias de desenvolvimento regional pensadas pelos diversos agentes. Rio Branco, capital do Estado do Acre, vem estabelecendo estratégias de desenvolvimento regional e local com base no Programa de Zoneamento Econômico, Ambiental, Social e Cultural de Rio Branco - ZEAS, considerado um instrumento estratégico e de sustentabilidade que contribuirá significativamente para o planejamento e reorientação das políticas públicas, dando suporte à gestão territorial e subsidiando a tomada de decisões do setor privado e da sociedade em geral. Este estudo, portanto, insere-se num esforço para entender as contribuições e estratégias integradas de desenvolvimento regional com uso do Geoprocessamento para levantamento de diversas informações para o ZEAS.
\end{abstract}

Palavras-chave: Geoprocessamento. Desenvolvimento regional. Zoneamento.

\begin{abstract}
With the increasing demand of information by governments and society, whether rural or urban, expressed in different zonings, the GIS has been an essential tool because it uses mathematical and computational techniques for the treatment of geographic information and has influenced so increasing areas of Mapping, Analysis of Natural Resources, Transport, Communication, Planning, Regional and Rural. This has contributed greatly to the regional development strategies designed by the various agents. Rio Branco, capital of Acre, is establishing strategies for regional and local development based on the Program Zoning Economic, Environmental, Social and Cultural Rio Branco (ZEAS), considered a strategic tool and sustainability will contribute significantly to the planning and reorientation of public policies, supporting and subsidizing land management decision-making in the private sector and society in general. This study, therefore, is part of an effort to understand the contributions and integrated regional development with the use of GIS to survey various information for ZEAS.
\end{abstract}

Keywords: GIS. Regional development. Zoning. 


\section{INTRODUÇÃO}

Rio Branco, a capital do Estado do Acre, vem estabelecendo estratégias de desenvolvimento regional e local com base no ZEAS. Esse programa é considerado um instrumento estratégico fundamentado na Sustentabilidade e contribuirá, significativamente, para o planejamento e reorientação das políticas públicas, dando suporte à gestão territorial e subsidiando a tomada de decisões do setor privado e da sociedade em geral. Nesse sentido, na execução do ZEAS, várias foram as contribuições e estratégias integradas com uso do Geoprocessamento para levantamento de diversas informações, dentre elas: os aspectos do solo (diagnóstico), dinâmica do desmatamento, tipologias florestais, aptidão à mecanização e outros.

A coleta de informações sobre a distribuição geográfica de recursos minerais, propriedades, animais e plantas sempre foi uma parte importante das atividades nas sociedades organizadas. Até recentemente, no entanto, isso era feito apenas em documentos e mapas em papel; o que impedia uma análise que combinasse diversos mapas e dados. Com o desenvolvimento, na segunda metade do século passado, da tecnologia de informática, tornou-se possível armazenar e representar tais informações em ambiente computacional, abrindo espaço para o aparecimento da disciplina de Geoprocessamento (CÂMARA, G. et. al., 2001).

Nesse sentido, considerando a capacidade das tecnologias de Sistemas de Informação Geográfica - SIG para armazenar, gerenciar e analisar diversos tipos de dados espacialmente referenciados, mostram-se como importante instrumento na realização de consultas e análises. A partir dos produtos gerados, os planejadores, seja regional ou localmente, tiveram acesso a novas ferramentas para pensar o desenvolvimento local e regional, tendo por parâmetro informações consolidadas.

$\mathrm{Na}$ abordagem proposta, destaca-se, primeiramente, a importância do Zoneamento do Município de Rio Branco como base para gestão. Do mesmo modo, evidencia-se como foram utilizadas as diversas técnicas de geoprocessamento na realização da análise das variáveis naturais e antrópicas no ZEAS. Os estudos envolvendo a integração dessas variáveis ambientais, sociais econômicas possibilitam uma integração entre geossistemas e Zoneamento Ecológico-Econômico como ferramentas de planejamento público e privado e estratégias de desenvolvimento para região.

A análise aqui proposta tem relevância significativa, dada a contribuição do Programa ZEAS para a tomada de decisões público-privadas. Dependendo da informação gerada, e dos estudos baseados no Programa, pode-se visualizar a importância dos geossistemas para o armazenamento, gerenciamento e análise espacial dessas informações.

Neste artigo, portanto, iremos trabalhar as principais contribuições e estratégias integradas com o uso do Geoprocessamento para o levantamento de diversas informações do ZEAS, com destaque para o diagnóstico dos tipos de solo, dinâmica do desmatamento, tipologias florestais e aptidão à mecanização agrícola no Município de Rio Branco.

A metodologia da pesquisa está voltada para uma produção bibliográfica e pesquisa documental, e para tal finalidade, procura-se inicialmente, contextualizar o surgimento dos principais conceitos abordados no trabalho: geoprocessamento, 
desenvolvimento e zoneamento, por meio de pesquisa bibliográfica em livros, artigos e periódicos (revistas, boletins, jornais).

Como se trata de pesquisa de revisão bibliográfica, o trabalho não apresentará um capitulo de resultados, e sim uma discussão ao final, fundamentado-se em uma proposta de leitura seletiva e analítica.

\section{DESENVOLVIMENTO}

\subsection{Geoprocessamento e Zoneamento: compreendendo os conceitos}

Atualmente, a tecnologia de Sistemas de Informação Geográfica-SIG, dada sua capacidade para armazenar, gerenciar e analisar diversos tipos de dados espacialmente referenciados, mostra-se como importante instrumento na realização de consultas e análises, gerando novas informações e permitindo uma melhor visualização da distribuição espacial de fenômenos demográficos, sociais, econômicos, agronômicos e ambientais (CATÃO e SARTOR, 2001).

Para os estudiosos, a principal função dos (SIGs) consiste em integrar as informações obtidas por sensoriamento remoto com outros dados espacialmente distribuídos (modelo numérico do terreno e declividade, entre outros). Os SIGs permitem, dessa forma, criar um modelo do mundo real ao integrarem dados de natureza diversa, voltados para uma aplicação em particular (FARINA, 2006).

Como será visto, o ZEAS utilizou a função integração de informações obtidas por sensoriamento remoto, que é proporcionada pelos SIGs para uma aplicação particular, nos vários diagnósticos do Zoneamento.

Nas palavras de Farina (2006, p. 03), no que se refere a aplicação do SIG para áreas urbanas:

\footnotetext{
o aperfeiçoamento crescente dos SIG e a automação dos procedimentos administrativos permitem estabelecer o processo de urbanização, com instrumentos cada vez mais sofisticados, que facilitam a tomada de decisões sobre operações urbanísticas com um elevado grau de complexidade. Aliado a esse processo de modernização, é preciso, ainda, transcender o planejamento setorial das cidades, que tem impedido a obtenção de uma visão global de suas problemáticas e a formulação de um modelo integrado para seu desenvolvimento futuro.
}

As técnicas de geoprocessamento certamente oferecerão subsídios básicos a cenários sustentáveis para a sociedade. No caso específico deste estudo, oferece um conjunto de informações para planejamento e execução de políticas públicas, bem como ações de iniciativa do setor privado.

Nesse sentido, existem diversos estudos que utilizam técnicas de geoprocessamento para criação de sistemas, mapeamento de áreas e etc. Desse modo, os dados obtidos pelos sensores orbitais permitem, graças a suas resoluções temporal, espacial e espectral, captar tendências de expansão das áreas urbanas com precisão e registrar, periodicamente, as relações indiretas entre os fenômenos urbanos e seu ambiente regional. Os SIGs representam, portanto, uma potente ferramenta de apoio à decisão, por meio da integração de dados para análise, 
provenientes de diferentes fontes (sensores orbitais, GPS, mapas temáticos analógicos, informação alfanumérica) e da modelagem de diversos processos que ocorrem no mundo real (FARINA, 2006).

Como visto, os SIGs representam um suporte para análise multitemporal nas mais diversas áreas. Fujaco et. al. (2010), por exemplo, fazem uma análise das mudanças no uso e ocupação do Parque Estadual do Itacolomi (MG) por meio de técnicas de geoprocessamento. Segundo os autores, numa primeira fase, foi realizada a fotointerpretação das fotografias aéreas com 0 auxilio de um estereoscópico de espelhos, na qual foram definidas as diversas classes de uso e ocupação. Após a fotointerpretação em laboratório, as fotografias aéreas foram georreferenciadas com o software Arcview ${ }^{\circledR} 9.2$ e inseridas em um ambiente SIG. No caso da imagem Ikonos, o mapeamento das diferentes classes foi realizado diretamente sobre a imagem.

As técnicas de geoprocessamento, portanto, são utilizadas como ferramenta de apoio nas mais diversas áreas: apoio à gerência de pavimentos em estradas florestais (EMMERT, F. et. al., 2010); uso de geoprocessamento na estimativa da perda de solo em microbacia hidrográfica do semiárido brasileiro (LOPES, F. B et. al., 2011); investigação da qualidade das águas em reservatório do semiárido usando geoprocessamento e análise multivariada. (ALEXANDRE, DEBORAH M.B. et. al., 2010); Circuitos Turísticos de Minas Gerais: uma análise a partir de ferramentas de geoprocessamento (TAVARES, J. M. et. al., 2010).

Observa-se que a análise complexa e integrada de diversas áreas e sua junção tem nas técnicas de geoprocessamento uma ferramenta extremamente importante, que alia diversas variáveis para compreensão do objetivo proposto.

Para o Zoneamento Ecológico-Econômico, essas técnicas são de relevada importância, pois possibilitam estudos envolvendo a integração de variáveis ambientais, importantes ao planejamento e gestão ambiental.

Os Zoneamentos são importantes instrumentos para se criar classes de uso e ocupação do solo, da flora e etc, de modo a disciplinar a utilização dos recursos ambientais da área.

Segundo Steinberger e Romero (2000), o Zoneamento EcológicoEconômico consiste na busca de indicadores que expressam a associação apropriada entre as diversas variáveis que compõem as dimensões que orientam o desenvolvimento territorial. Nas palavras de Pereira et. al. (2011, p.02):

\footnotetext{
por ter esse caráter indicativo, o ZEE oferece indicadores e índices que condensam informações, que podem ser utilizadas como elementos norteadores para monitorar, acompanhar e avaliar o planejamento, ou seja, pode ser utilizado como instrumento de gestão territorial. Com o ZEE é possível orientar a formulação de políticas públicas setoriais com maior precisão e consistência, orientar decisões no âmbito da gestão do território, orientar organismos governamentais e não governamentais na intervenção social no âmbito municipal, orientar contratos entre iniciativas privadas e governos, bem como servir de referência para ações judiciais de caráter público. Portanto, serve de base para a gestão social do território, tendo em vista que o Programa Territórios da Cidadania, como política pública federal, adotou um modelo de gestão social que se pauta nos princípios da participação, descentralização, democracia e transparência.
} 
Alguns autores afirmam que a origem dos zoneamentos no Brasil está relacionada às necessidades advindas das análises a respeito de impactos ambientais na década de 1970, o que adquiriu força com a promulgação da Lei $n^{\circ}$ 6.938, em 1981, que estabelece os objetivos e as normas da Política Nacional de Meio Ambiente - PNMA, fazendo referência ao zoneamento ambiental como instrumento de política (PEREIRA et. al., 2011).

Foi possível verificar que, tanto para os Zoneamentos Ecológico-Econômicos quanto para outras tantas áreas, as técnicas de geoprocessamento são relevantes, pois possibilitam estudos envolvendo a integração de variáveis ambientais e antrópicas importantes ao planejamento e gestão ambiental.

\subsection{Zoneamento Econômico, Ambiental, Social e Cultural de Rio Branco (ZEAS) ${ }^{1}$}

A atribuição de promover estudos sobre o zoneamento, a elaboração da política de desenvolvimento municipal, integrada e sustentável, vem sendo executada no âmbito do ZEAS.

Nesse contexto, o objetivo do Programa ZEAS é contribuir para o planejamento e reorientação das políticas públicas da área rural, dando suporte à gestão territorial e subsidiando a tomada de decisões do setor privado e da sociedade em geral, visando promover o desenvolvimento sustentável e equitativo no Município de Rio Branco.

Esse Programa foi instituído pelo Decreto 1.076 de 10 de março de 2006, e permitirá estabelecer diretrizes, planejar e implementar políticas, projetos e ações visando conciliar o processo de desenvolvimento econômico com a conservação ambiental, a geração de emprego, renda, melhoria da qualidade de vida e o respeito aos aspectos sociais e culturais da vida da população do município.

A Secretaria Executiva do Programa ZEAS é constituída dos órgãos:

$\begin{array}{ll}\checkmark & \text { Secretaria Municipal de Meio Ambiente - SEMEIA; } \\ \checkmark & \text { Secretaria Municipal de Governo e Articulação Política - SEGOV; } \\ \checkmark & \text { Secretaria Municipal de Agricultura e Floresta - SAFRA; } \\ \checkmark & \text { Secretaria Municipal de Planejamento - SEPLAN; } \\ \checkmark & \text { Fundação Municipal de Cultura Garibaldi Brasil - FGB; } \\ \checkmark & \text { Empresa Brasileira de Pesquisa e Agropecuária - Embrapa; e, } \\ \checkmark & \text { Secretaria Estadual de Meio Ambiente - SEMA. }\end{array}$

O ZEAS vem atuando em algumas áreas, denominadas prioritárias em função da urgência do conhecimento do seu potencial e restrições de uso. Essas áreas são os 11 Projetos de Assentamento do Instituto Nacional de Colonização e Reforma Agrária, os sete polos agroflorestais e o Seringal São Francisco do Espalha. Em 2010, o Programa deu continuidade às suas atividades inerentes ao diagnóstico dos recursos naturais, socioeconômico da área rural e cultural-político.

\footnotetext{
${ }^{1}$ Informações obtidas junto à Secretaria Municipal de Planejamento da Prefeitura de Rio Branco Relatórios de Gestão 2010 e 2011.
} 
No período de 2007 a 2010, o Programa ZEAS conquistou avanços muito significativos que contribuirão para o cruzamento das informações para a elaboração do Mapa de Gestão do município.

A gestão territorial do município passa obrigatoriamente pela forma de colonização dessas terras e pela história do povo acreano. Assim, com uma metodologia voltada especificamente para a gestão do território a partir da identidade dos grupos sociais que formaram territórios específicos no município, o Programa ZEAS vem definindo as zonas para gestão, pautada nessa forma de ocupação e organização dos grupos sociais, bem como da diversidade cultural que ocupa o espaço geográfico municipal.

Dessa forma, após vários levantamentos primários, o Programa ZEAS - só avançou com a elaboração de uma metodologia específica que considera os territórios como zonas de gestão. Assim foi possível identificar os territórios em Rio Branco e, posteriormente, elaborar o Mapa de Gestão Territorial preliminar que vem sendo aprimorado.

Até o momento, o Programa Zeas gerou a $5^{a}$ Versão do Mapa de Gestão, que aguarda a aprovação pelo Comitê Técnico da metodologia utilizada nesta versão. Essas atividades resultarão no Mapa de Gestão Territorial de Rio Branco e em um Documento Síntese, onde estarão definidas as diretrizes de uso das zonas. Espera-se chegar a um Mapa de Gestão que respeite os territórios criados pelos grupos sociais, bem como, que potencialize o uso dos recursos de forma mais adequada, buscando a proteção e conservação dos bens naturais e culturais do município.

As ações realizadas no ano de 2010 subsidiaram os resultados finais pertinentes ao diagnóstico e prognóstico do meio físico-biótico, socioeconômico e cultural-político; a elaboração do Plano de Gestão do Município de Rio Branco e mapa de gestão, na escala de 1:100.000, além de propor as Zonas de Gestão e implementação de ações, tendo como variáveis os Sistemas Territoriais Produtivos, as limitações e as potencialidades ambientais, a dinâmica socioeconômica, cultural e política.

\section{DISCUSSÃO}

\subsection{Análise por Geoprocessamento da Aptidão a Mecanização do Município de Rio Branco}

O estudo de viabilidade e aptidão mecânica de áreas representa um importante instrumento para planejamento e aproveitamento do potencial produtivo em diversas regiões. No Brasil, a utilização de técnicas de geoprocessamento para compreensão dos fatores ligados à_terra são relativamente recentes. Esses estudos nascem a partir da necessidade de identificar quais as técnicas corretas de utilização agronômica sustentada das terras, que requer, para tanto, conhecimento de suas características intrínsecas e extrínsecas, permitindo avaliar, cientificamente sua capacidade real de suporte, bem como sua vulnerabilidade e seu manejo adequado.

Analisando os boletins técnicos produzidos pelo ZEAS, percebe-se que a análise por geoprocessamento da aptidão à mecanização no Município de Rio Branco envolveu, inicialmente, a adequação cartográfica das bases do Programa ZEAS, em relação à escala (1:10.000) e às projeções cartográficas (UTM SAD 69). Foram utilizadas bases como: 
solos, limites municipais, rede de drenagem, vias de circulação, Áreas de Preservação Permanente-APP, uso e cobertura do solo (CARMO et. al., 2008b).

Conforme os analistas vaticinam, a obtenção das classes de aptidão à mecanização baseou-se em procedimentos metodológicos de "Pesos e Notas". Esses pesos e notas, baseando-se no mapa de solos da área e no banco de dados modelado por variáveis edáficas (drenagem, relevo, profundidade, concreções e textura) para cada unidade de mapeamento de solo ${ }^{2}$, atribuiu-se as notas para cada categoria/legenda, tendo variação de 1 a 10.

-As notas foram atribuídas às classes de aptidão à mecanização, sendo que as características mais favoráveis receberam as menores notas e as menos favoráveis, as maiores, como descritas na Tabela abaixo.

Tabela 1. Notas por classe de aptidão dos solos à mecanização agrícola

\begin{tabular}{lc}
\hline Classe de aptidão & Nota \\
\hline Apta $(\mathrm{A})$ & 1 \\
\hline Restrição leve (RL) & 3 \\
\hline Restrição moderada (RM) & 6 \\
\hline Restrição severa (RS) & 8 \\
\hline Inapta (I) & 10 \\
\hline
\end{tabular}

Fonte: Boletim Técnico no 004 - ZEAS (CARMO et. al. 2008b). ulteriores:

Desse modo, considerando os pesos e notas, bem como as informações os pesos referem-se ao valor (\%) de cada plano de informação (mapas
temáticos). O total dos planos de informação vale $100 \%$. Assim, a
distribuição dos valores por mapa temático é relacionada à importância
da temática dentro da análise, neste caso, aptidão à mecanização para o
município de Rio Branco. Os planos de informação utilizados nesta
análise foram os mapas de variáveis morfológicas e de variáveis físicas,
ambos após atribuição das notas. Para a análise em questão, foram
atribuídos $70 \%$ para o mapa de variáveis morfológicas e $30 \%$ para o de
variáveis físicas. Após atribuição das notas para as categorias/legendas e
pesos para os planos de informação (mapas temáticos), realizou-se o
cruzamento dos mapas. (CARMO et. al., 2008, p.31).

Em relação à análise integrada por geoprocessamento dos dados analíticos (parâmetros avaliativos) ${ }_{\perp}$ esta foi baseada nos preceitos do Sistema de Análise Geo-Ambiental por Geoprocessamento do SIG SAGA/UFRJ. Esse SIG foi desenvolvido pelo Laboratório de Geoprocessamento Aplicado da Universidade Federal do Rio de Janeiro (UFRJ) (XAVIER-DA-SILVA, 2001 apud CARMO et. al. 2008b).

\footnotetext{
2 Área de distribuição geográfica de, no mínimo, uma classe de solo como corpos naturais, determinados por um conjunto de relações e propriedades observáveis na natureza.
} 

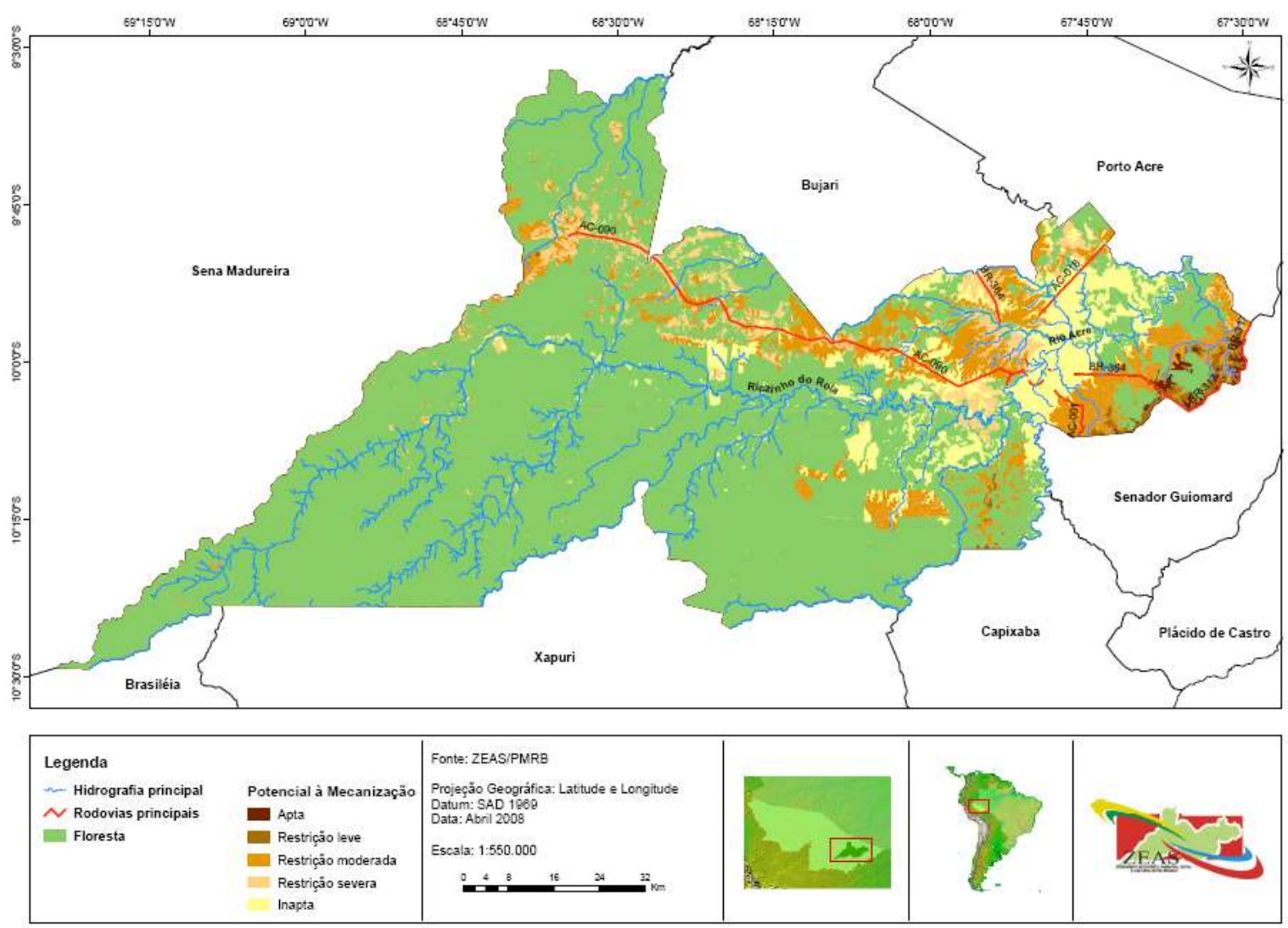

Figura 01. Aptidão dos solos à mecanização agrícola para o município de Rio Branco-AC. Fonte: CARMO, Lúcio Flávio Zancanela do et. al. (2008b).

$\mathrm{Na}$ análise de Carmo et. al. (2008b), quanto às técnicas de geoprocessamento utilizadas no trabalho, ele discorre que o cruzamento dos mapas temáticos foi realizado em ambiente de Sistemas de Informação Geográfica SIG, utilizando-se o software ArcGIS 9.2 no módulo de operações ArcMap. Após o cruzamento- que considerou e realizou as operações matemáticas de pesos e notas para cada área do terreno, obteve-se o mapa preliminar de Aptidão à Mecanização Agrícola para todo o Município de Rio Branco. Além do mapa com informações espacializadas, foram gerados dados numéricos (hectare e percentagem) das áreas ocupadas por cada classe de aptidão.

\subsection{Prospecção de dados e Cartografia dos Solos no Município de Rio Branco}

$\mathrm{Na}$ análise das técnicas de geoprocessamento utilizadas para levantamento dos dados dos tipos de solo no Município de Rio Branco, os estudiosos elaboraram revisão bibliográfica com o objetivo de obter informações a respeito da área de estudo e levantar perfis de solos descritos para a estruturação do banco de dados. Posteriormente, realizou-se a interpretação das imagens do sensor Shuttle Radar Topography Mission-SRTM de 2002, com pixel de 90 m, do acervo do Núcleo de Estudo de Planejamento de Uso da Terra da Universidade Federal de Viçosa-MG NEPUT, que cobre toda a área de estudo (CARMO et. al. 2008c). 
No estudo supramencionado, somou-se ao trabalho cartográfico o trabalho de campo que constou do levantamento e mapeamento dos solos, por meio de progressão em toda a área do município.

Como resultado da junção de técnicas de geoprocessamento e trabalho de coleta de dados em campo, foram obtidas uma legenda de identificação dos solos do município, seguindo parâmetros para elaboração da legenda final de identificação dos solos, acertos finais no mapeamento, revisão das descrições e interpretação dos resultados analíticos dos perfis, redação e organização do relatório final, assim como a elaboração do mapa de solos na escala de 1:100.000, conforme figura 03.
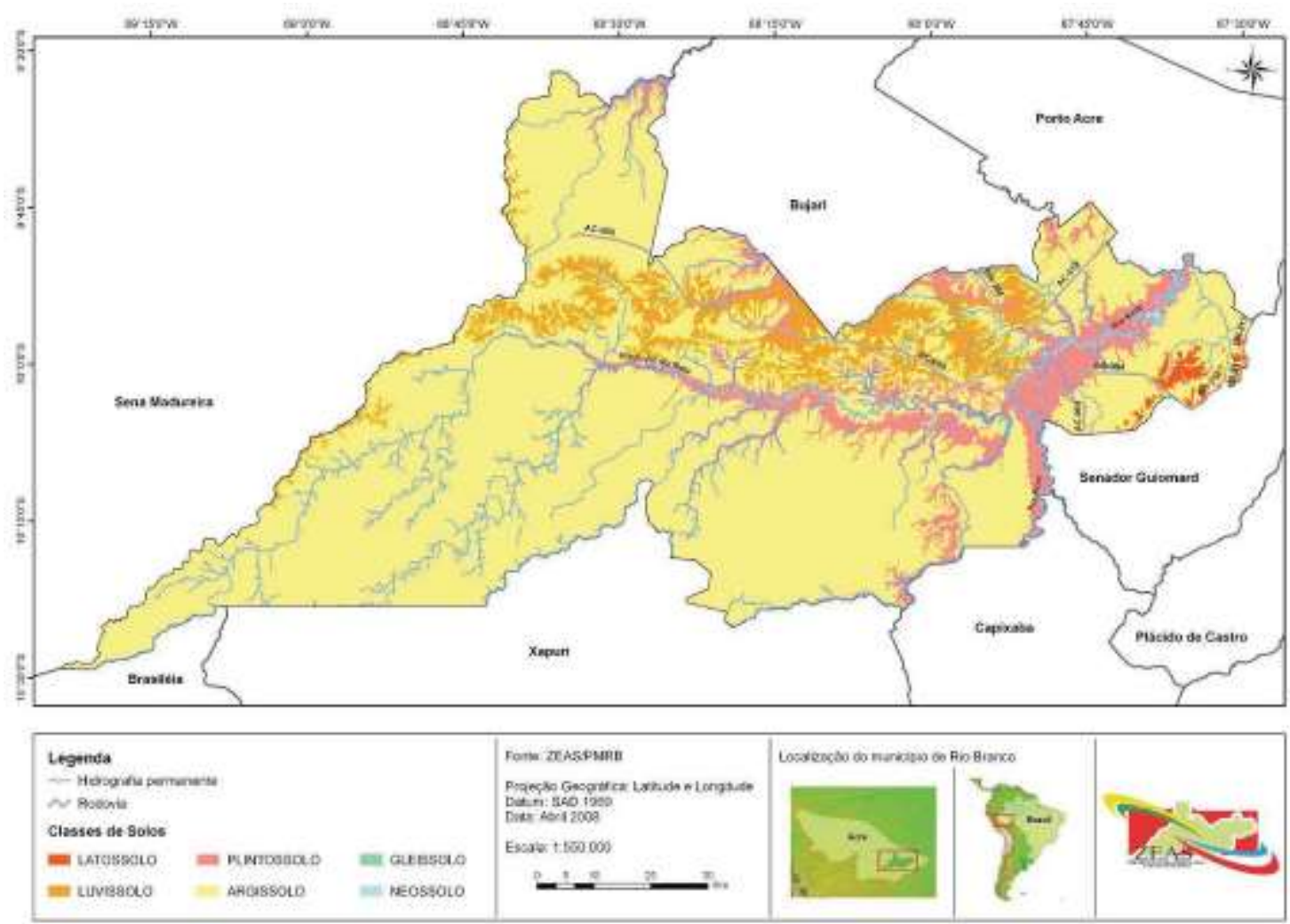

Figura 02. Distribuição das ordens de solos (1º nível categórico) do município de Rio Branco-AC na escala 1:100.000.

Fonte: CARMO, Lúcio Flávio Zancanela do et. al. (2008c).

Conforme os dados coletados no estudo sobre tipos de solo no Município de Rio Branco, os principais solos, em termos de primeiro nível categórico (Figura 03), pertencentes ao primeiro componente das unidades de mapeamento, em ordem decrescente de expressão territorial, são: Argissolos (78,67\%), Plintossolos $(11,83 \%)$, Luvissolos $(8,18 \%)$, Latossolos $(0,76 \%)$, Neossolos $(0,54 \%)$ e Gleissolos (0,02\%) (CARMO et. al. 2008b).

Cabe destacar também que, em relação às técnicas de geoprocessamento, o cruzamento dos mapas temáticos foi realizado em ambiente de SIG, utilizando-se o software ArcGIS 9.2 no módulo de operações ArcMap. Após o cruzamento, que considerou e realizou as operações matemáticas de pesos e notas para cada área do terreno, obteve-se o mapa preliminar de Aptidão à Mecanização Agrícola para todo o Município de Rio Branco. Além do mapa com 
informações espacializadas, foram gerados dados numéricos (hectare e percentagem) das áreas ocupadas por cada classe de aptidão (CARMO et. al. 2008b).

Neste estudo, deve-se destacar, ainda, a contribuição das técnicas de geoprocessamento para o mapeamento das áreas aptas à mecanização no Município, compreendendo os solos mais desenvolvidos (Latossolos e Argissolos Vermelhos), os quais apresentam requisitos favoráveis à prática agrícola, contribuindo, assim, para o desenvolvimento rural sustentável.

\subsection{Geoprocessamento e avaliação da dinâmica do desmatamento no Município de Rio Branco}

A expansão da fronteira agrícola na Amazônia, que tráz consequências catastróficas para a região, na fala de Loureiro (2009, p.21) "articula-se e é impulsionada, direta e mais intensamente, pelo mercado internacional e, muito menos, pela conjuntura e pelo mercado nacional".

Outra grave consequência desse processo na Amazônia, com destaque para o Estado do Pará e Mato Grosso, tem sido o acirramento dos conflitos no campo/floresta e exploração madeireira ilegal e aumento da taxa de desmatamento.

Como se sabe, os impactos ambientais ocasionados pelo desmatamento podem ser de grande magnitude, como a perda da biodiversidade, mudanças climáticas, perdas de produtividade do solo, interferência do ciclo hidrológico e de nutrientes, deslocamento e destruição de povos indígenas e suas tradições culturais (FEARNSIDE, 2005 e VIEIRA et al., 2005).

No Município de Rio Branco, o ZEAS tem procurado monitorar os impactos das ações predatórias na região, neste caso, relacionadas ao desmatamento. Busca contribuir para o planejamento e reorientação das políticas públicas, dando suporte à gestão territorial e subsidiando a tomada de decisões do setor privado e da sociedade em geral.

Para o diagnóstico da dinâmica do desmatamento no Município de Rio Branco, por meio de técnicas de geoprocessamento, foram necessárias três imagens Landsat para cobrir totalmente o município, a cada ano (Figura 04). Além dessas imagens de satélite e do mapa político municipal, foram utilizados mapas de Unidades de Conservação, APPs e Projetos de Assentamentos para análises da dinâmica do desmatamento. 


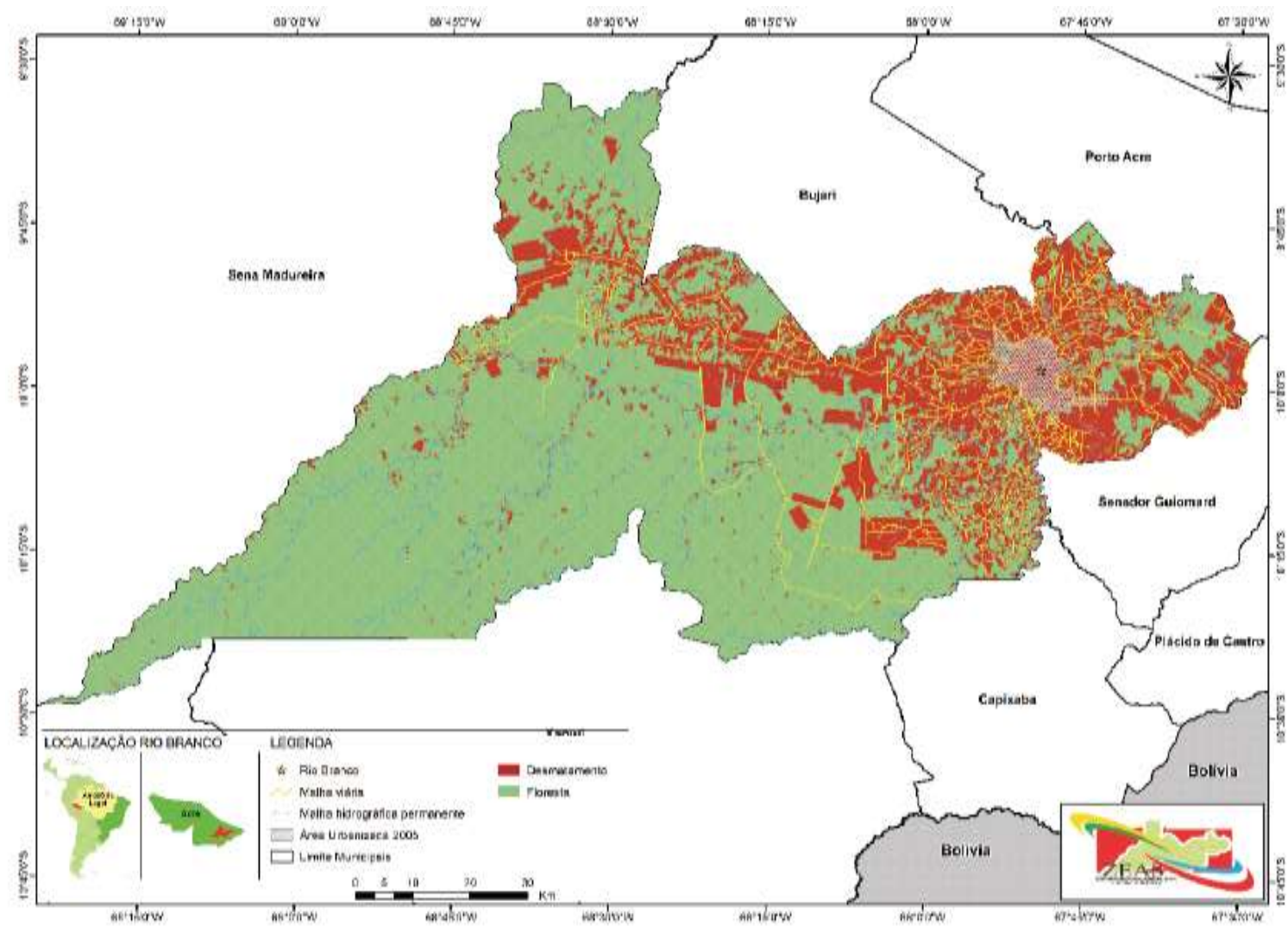

Figura 03. Localização da área de estudo e das imagens (órbita/ponto) do satélite Landsat utilizadas para o monitoramento do incremento do desmatamento no município de Rio Branco - AC. Fonte: SILVA, Sonaira Souza da- et. al. (2008).

Como resultado dos dados analisados, verificou-se que o desmatamento concentra-se, principalmente, na região leste do Município de Rio Branco, no entorno da área urbana, distribuindo-se, também, ao longo das BR-364 (trecho Rio Branco-Porto Velho), BR-317, AC-090 e AC-040. Além disso, há manchas de desflorestamento ao longo dos cursos de rios e igarapés (Figura 05) (SILVA et. al. 2008). 


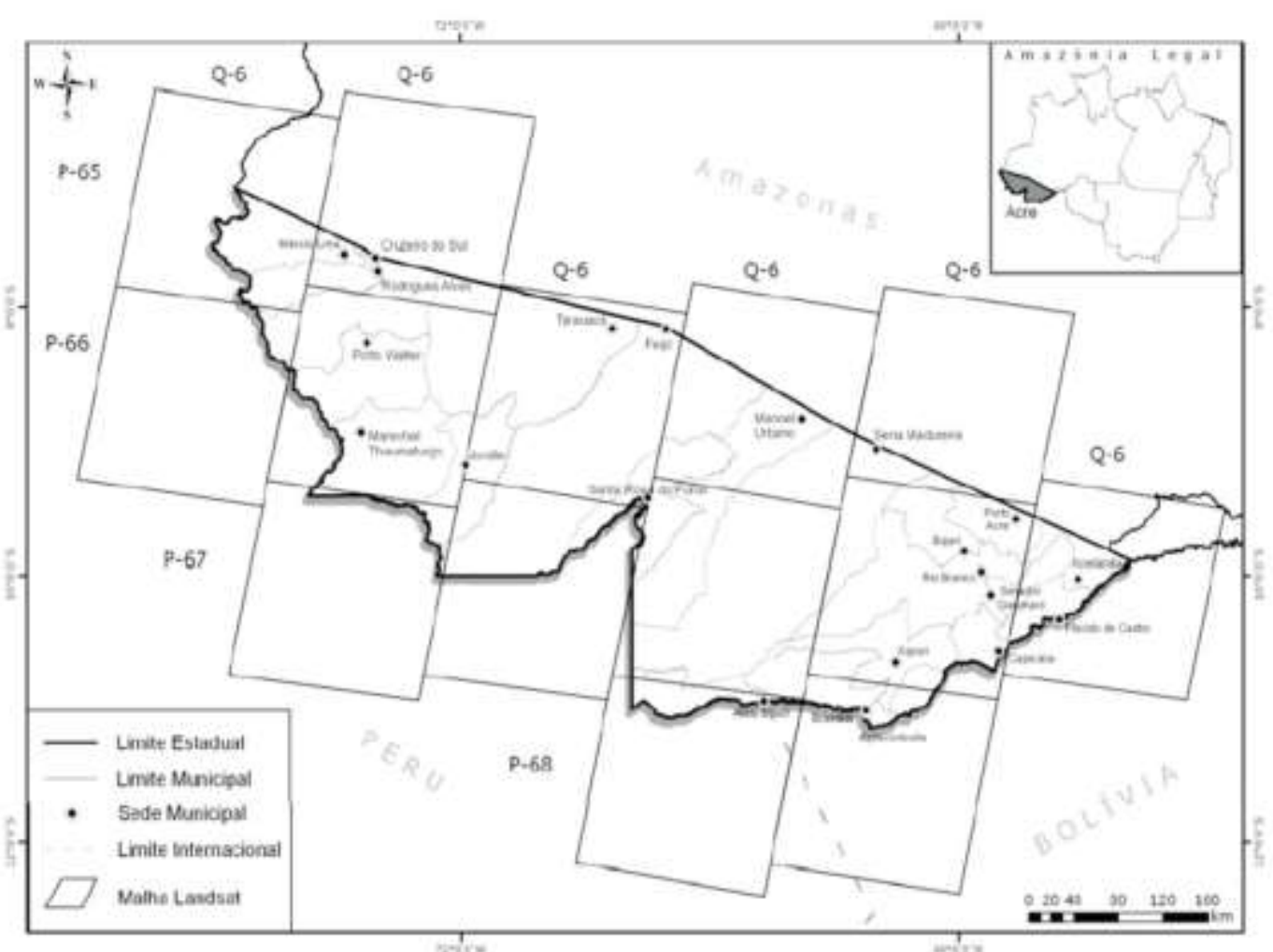

Figura 04. Distribuição das áreas desmatadas no município de Rio Branco-AC até 2007. Fonte: SILVA, Sonaira Souza da -et. al. (2008).

O processo de desmatamento na Amazônia gera uma paisagem de fragmentação florestal cercada por campos de pastagens, agricultura e zonas urbanas. Os fatores negativos dessa ação humana são evidentes, pois essa fragmentação promove, além de perdas de biodiversidade, alterações no ciclo hidrológico e aumento dos riscos de incêndios florestais.

Silva (2008) destaca que o processo de desmatamento fragmentado torna a floresta remanescente mais suscetível aos incêndios florestais, provocando a morte de árvores e de outros componentes deste ecossistema, além da emissão de milhões de toneladas de gases do efeito estufa para a atmosfera.

O monitoramento periódico feito na Amazônia por imagens de satélite e outras técnicas de geoprocessamento possibilitam aos Governos, Organizações Não-Governamentais - ONGs e outros atores, um acompanhamento das taxas de desmatamento, e uma maior articulação para combatê-lo. Em Rio Branco, tem possibilitado um acompanhamento do processo de desenvolvimento, criando condições para manter preservada a floresta, sem deixar de alcançar índices satisfatórios de crescimento.

\subsection{Tipologias Florestais no Município de Rio Branco e Análise por Geoprocessamento.}

Em relação ao método de estudo e às técnicas de geoprocessamento utilizadas para a verificação das tipologias florestais no Município de Rio Branco, foram realizadas interpretações de imagens de satélite em duas etapas. A primeira constou da interpretação visual, utilizando imagens do satélite Landsat TM5, bandas 3, 4, 5 - ano 2004, e imagens CBERS de 2005 na escala 1:100.000 (LANI, et. al., 2008). 
Prosseguindo em sua análise, Lani et. al. (2008, p.19) verificaram que:

para separar os diferentes padrões de tipologias florestais nas imagens, foi utilizada a interpretação visual, em que foram sobrepostas as tipologias identificadas no ZEE Fase II (ACRE, 2006) sobre as imagens de satélite de 2005, para correção dos polígonos. A classificação das diferentes fisionomias florestais foi realizada comparando-se as legendas do ZEE Fase II, os estudos recentes realizados na área do Seringal São Francisco do Espalha, em três pontos da Rodovia Transacreana e dados de alguns inventários já realizados no Município e em seu entorno em áreas particulares com manejo florestal.

É importante frisar que a atualização do mapeamento da vegetação do Município de Rio Branco, diagnosticando as condições atuais da cobertura florestal, permitirá a correção de pequenas falhas no mapeamento realizado anteriormente, tendo em vista que o município possuía, em 2005, cerca de $26 \%$ da sua superfície desflorestada.

LANI et. al. (2008) afirmam que, para o Município de Rio Branco, baseando-se nas técnicas acima descritas, foram identificados dez tipos de tipologias florestais predominantes que são: FAB+FAP (floresta aberta com bambus + floresta aberta com palmeiras), FD (floresta densa), FAB+FAP+FD (floresta aberta com bambus + floresta aberta com palmeiras + floresta densa), FAB +FD (floresta aberta com bambus +floresta densa), FABO (floresta aberta com bambus ombrófila), FABO+FAP (floresta aberta com bambus ombrófila + floresta com palmeiras), FAP (floresta aberta com palmeiras), FAP +FAB (floresta aberta com palmeiras + floresta aberta com bambus), FAP+FAB+FD (floresta aberta com palmeiras + floresta aberta com bambus + floresta densa), FAP+FD (floresta aberta com palmeiras + floresta densa), FAP+FD+FAB (floresta aberta com palmeiras + floresta densa + floresta com bambus), evidenciados na Figura 05. 


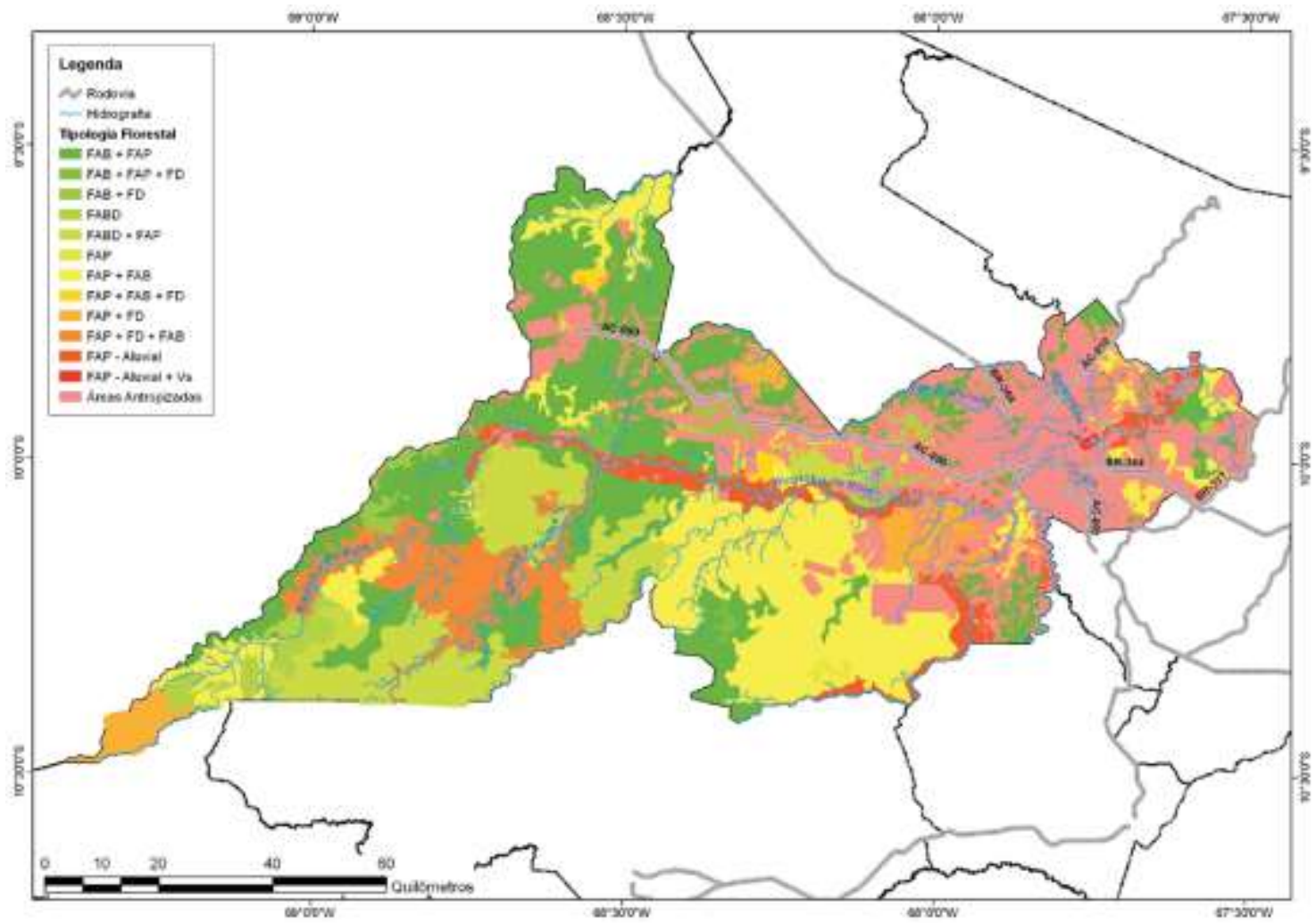

Figura 05. Mapa de tipologias florestais do Município de Rio Branco - AC. Fonte: LANI, João Luiz et. al. (2008).

O monitoramento das tipologias florestais, ou a atualização da vegetação do Município de Rio Branco ampliou o reconhecimento de mais duas tipologias florestais, ampliando para 12 o número registrado que são: FAP+Aluvial (floresta aberta com palmeiras + floresta aluvial), FAP+Aluvial+Vs (floresta aberta com palmeiras + floresta aluvial + vegetação secundária). Pode-se concluir, com o estudo conduzido pelo ZEAS, utilizando-se técnicas de geoprocessamento, que o município ainda preserva um maciço de floresta bastante significativo, 73,88 \%, e grande parte dele está localizado na bacia do Riozinho do Rola.

Essa Bacia é de elevada importância para o Rio Acre, principal rio do Município e Estado. Além disso, como recomendações gerais, o estudo aponta que deve-se realizar uma interpretação da cobertura vegetal utilizando imagens de satélite mais recentes, pois a interpretação realizada retrata a estrutura e a qualidade da vegetação no ano de 2005 (LANI, 2008).

\section{CONCLUSÃO}

Como se viu, a análise complexa e integrada do meio ambiente e de suas relações interdependentes com a sociedade, no caso estudado dos Zoneamentos Ecológico-Econômicos, tem nos geossistemas uma ferramenta bastante útil, que possibilita estudos envolvendo a integração de variáveis ambientais, sociais e antrópicas importantes ao planejamento e gestão ambiental.

Conforme o proposto, foram analisadas as contribuições dessas técnicas de geoprocessamento, como ferramentas para as informações do ZEAS, com 
destaque para diagnóstico dos tipos de solo, dinâmica do desmatamento, tipologias florestais e aptidão à mecanização agrícola no Município de Rio Branco.

Em relação à Aptidão à Mecanização Agrícola, com suporte das técnicas de geoprocessamento ${ }_{\perp}$ obteve-se o mapa preliminar para todo o Município de Rio Branco. Além do mapa com informações espacializadas, foram gerados dados numéricos (hectare e percentagem) das áreas ocupadas por cada classe de aptidão de solos, possibilitando a ampliação da mecanização, consequentemente, maior produção e preservação ambiental.

No que se refere à dinâmica do desmatamento, os estudos do ZEAS demonstram, por meio das ferramentas do SIG, que o desmatamento concentrase, principalmente, na região leste do Município de Rio Branco, no entorno da área urbana, distribuindo-se, também, ao longo das BR-364 (trecho Rio Branco-Porto Velho), BR-317, AC-090 e AC-040. Além disso, há manchas de desflorestamento ao longo dos cursos de rios e igarapés

Do mesmo modo, a análise das tipologias florestais ou a atualização da vegetação do Município de Rio Branco ampliou o reconhecimento de mais duas tipologias florestais, expandindo para 12 o número registrado. Pôde-se concluir, com o estudo conduzido pelo ZEAS, que o Município ainda preserva um maciço de floresta bastante significativo, 73,88 \%, e grande parte dele está localizado na bacia do Riozinho do Rola, uma das mais importantes do Estado do Acre.

Nesse contexto, o instrumental disponibilizado pelas ferramentas SIG foi essencial para atingir os objetivos do Programa ZEAS, contribuindo, assim, para o planejamento e reorientação das políticas públicas da área rural; dando suporte à gestão territorial e subsidiando a tomada de decisões do setor privado e da sociedade em geral.

No geral, o artigo demonstra a importância dos geossistemas para o armazenamento, gerenciamento e análise espacial das informações do ZEAS, contribuindo para seu objetivo de promover o desenvolvimento sustentável e equitativo no Município de Rio Branco.

Por fim, a partir das técnicas de geoprocessamento e da utilização de ferramentas do SIG no ZEAS, observa-se um leque de viabilidades que podem subsidiar o planejamento e aplicação de um ordenamento territorial eficaz, respeitando especificidades econômicas, sociais e ambientais que possibilitem fomentar o desenvolvimento regional sustentável, trazendo uma visão estratégica, minimizando os impactos ambientais em algumas regiões do Município de Rio Branco.

\section{REFERÊNCIAS}

ALEXANDRE, Deborah Mithya Barros et. al. Investigação da qualidade das águas em reservatório do semiárido usando geoprocessamento e análise multivariada. Revista Ciência Agronômica, Oct.2010, Vol. 41 Issue 4, p554-561, 2010.

CÂMARA, G.; DAVIS.C.; MONTEIRO, A.M.; D'ALGE, J.C (2001). Introdução à Ciência da Geoinformação. São José dos Campos, INPE, 2001. 
CARMO, Lúcio Flávio Zancanela do et. al. Diagnóstico dos recursos naturais do Pólo Agroflorestal Geraldo Fleming, no Município de Rio Branco-AC. / Lúcio Flávio Zancanela do Carmo, Raimundo Nonato de Souza Moraes, Marconde Maia Ferreira, .Rio Branco: PMRB, 2008. (Boletim de Pesquisa, 008). 50p.: il. Programa de Zoneamento Econômico, Ambiental, Social e Cultural de Rio Branco-AC, ZEAS.

CARMO, Lúcio Flávio Zancanela do et. al. Aptidão dos solos para mecanização agrícola nas áreas desmatadas do município de Rio Branco - AC / Lúcio Flávio Zancanela do Carmo, Raimundo Nonato de Souza Moraes e Sonaira Souza da Silva. _Rio Branco: PMRB, 2008b. (Boletim de Pesquisa, 004). 50p.: il.

CARMO, Lúcio Flávio Zancanela do et. al. Diagnóstico dos Tipos de Solos do Município de Rio Branco - AC. Lúcio Flávio Zancanela do Carmo, Raimundo Nonato de Souza Moraes (Editores). Rio Branco: PMRB, 2008c. (Boletim Técnico, 001). 62p.: il. Programa de Zoneamento Econômico, Ambiental, Social e Cultural de Rio Branco-AC, ZEAS.

CATÃO, G. A.; SARTOR, C. E. O Uso da Tecnologia SIG na Análise das Desigualdades Socioespaciais na Metrópole do Rio de Janeiro. In: GIS BRASIL 2001, 1, 2001. Curitiba. Anais...Curitiba, 2001.

EMMERT, Fabiano et. al. Geoprocessamento como ferramenta de apoio à gerência de pavimentos em estradas florestais. Ciência Florestal, Santa Maria, v. 20, n. 1, p. 81-94, jan./mar., 2010.

FARINA, Flávia C. Abordagem sobre técnicas de geoprocessamento aplicadas ao planejamento e gestão urbana. Cadernos EBAPE. BR, v., nº 4, Dez. 2006.

FEARNSIDE, P. M. Desmatamento na Amazônia brasileira: história, índices e conseqüências. Megadiversidade, v. 1, n. 1, p. 113-123, 2005.

FUJACO, Maria Augusta Gonçalves et. al. Análise multitemporal das mudanças no uso e ocupação do Parque Estadual do Itacolomi (MG) através de técnicas de geoprocessamento. REM: R. Esc. Minas, Ouro Preto, 63(4): 695-701, out. dez. 2010.

LANI, João Luiz et. al. Tipologias Florestais do Município de Rio Branco - AC. João Luiz Lani, Marco Antônio Gomes, Nádia Waleska Valentim Pereira. - Rio Branco: PMRB, 2008. (Boletim Técnico, 015). 54p.: il. Programa de Zoneamento Econômico, Ambiental, Social e Cultural de Rio Branco-AC, ZEAS.

LOPES, Fernando Bezerra. Applied geoprocessing for soil loss estimation in a Brazilian semiarid watershed. (English).Revista Agro@mbiente On-line, Vol.5 Issue 2, p88-96, 8p, 2011.

LOUREIRO, Violeta Refkalefsky. A Amazônia no Século XXI: Novos e renovados dilemas no processo de desenvolvimento. In: $33^{\circ}$ ENCONTRO ANUAL DA ANPOCS, 2009. 
PEREIRA, José Roberto. Gestão social dos territórios da cidadania: o zoneamento ecológico-econômico como instrumento de gestão do território noroeste de Minas Gerais. Cad. EBAPE. BR, v. 9, n 3, artigo 3, Rio de Janeiro, 2011

SILVA, Sonaira Souza da et. al. Dinâmica do desmatamento em Rio Branco-AC /, Judson Ferreira Valentim, Eufran Ferreira do Amaral, Antônio Willian Flores de Melo. _Rio Branco: PMRB, 2008. (Boletim de Pesquisa, 003). 46p.: il. Programa de Zoneamento Econômico, Ambiental, Social e Cultural de Rio Branco-AC, ZEAS.

STEINBERGER, M.; ROMERO, M. B. Reflexões preliminares sobre as dimensões demográficas urbanas do zoneamento ecológico-econômico. In: ENCONTRO NACIONAL DA ABEP, 12, Caxambu, Anais..., ABEP: Caxambu, 2000.

TAVARES, Jean Max et. al . Circuitos Turísticos de Minas Gerais: uma análise a partir de ferramentas de geoprocessamento. Turismo em Análise, Vol. 21 Issue 1, p25-47, 23p, 2010.

VIEIRA, I. C. G.; SILVA, J. M. C. da; TOLEDO, P. M. de. Estratégias para evitar a perda de biodiversidade na Amazônia. Estudos Avançados, v. 19, n. 54, p. 153164, 2005.

Submetido em 13/09/2013.

Aprovado em 27/10/2015.

\section{Sobre a autora}

Lorena Costa Irmão

Mestranda em Desenvolvimento Regional(UFAC-2013), Especialista em Geoprocessamento Aplicado à Análise Ambiental (UNINORTE-AC) e Técnica em Assuntos Educacionais da Universidade Federal do Acre - UFAC/Brasil.

Endereço: Rua São Judas Tadeu n. 21, Conjunto Universitário. 69917-696 -Rio Branco, AC, Brasil. E-mail: lorenaacre@hotmail.com

\section{Raimundo Cláudio Gomes Maciel}

Doutor em Economia Aplicada pela Universidade Estadual de Campinas - UNICAMP. Professor da Universidade Federal do Acre - UFAC.

Endereço: Rua Mississipe, 213, Residencial Iolanda. 69918-892 - Rio Branco, AC, Brasil.

E-mail: rcgmaciel@ufac.br 